\title{
Refraction of 1-year-old children after atropine cycloplegia
}

\author{
R. M. INGRAM \\ From the Kettering and District General Hospital, Kettering
}

SUMMARY The refractions of 1648 children aged 11 to 13 months are reported. Atropine $1 \%$ was used for cycloplegia. $11.83 \%$ of the children had bilateral hypermetropia of +2.00 or more D. $13.23 \%$ of them had +1.50 or more D astigmatism in one or both eyes, and $6.5 \%$ had anisometropia. Anisometropia was significantly $(P=0.000001 \%)$ associated with bilateral hypermetropia, but even more significantly $(P=0.0000004 \%)$ associated with astigmatism of +1.50 or more $D$ in one or both eyes.

Cyclopentolate was used in our pilot study (Ingram et al., 1979) for reasons of convenience, but its cycloplegic effect has not been proved (Davidson, 1976). Atropine is accepted generally as the most efficient cycloplegic drug, and the true range of refractions at age 1 year would be more accurately recorded after 'atropinisation'. This is a report of the refractions of 16481 -year-old children examined after 'full atropinisation'. The findings are compared with those of other 1-year-old children refracted after instillation of cyclopentolate in a subsequent publication (Ingram and Barr, 1979).

\section{Sample of children}

The children were all born between 1 January 1974 and 31 December 1976. They were registered at the time of their first birthday under one of the partners in seven adjacent group general medical practices in the Kettering district.

\section{Methods}

Mothers were introduced to the idea of vision screening by the health visitors when the child had a hearing test at the age of 9 months. Those wishing to have their children's eyes examined were subsequently issued with written instructions on how to instil $1 \%$ atropine ointment twice daily for the 4 days preceding their appointment. The examinations were carried out in the respective general practitioners' premises.

The plan was to screen the children during the

Address for reprints: $\operatorname{Dr}$ R. M. Ingram, Kettering and District General Hospital, Rothwell Road, Kettering, Northamptonshire NN16 8UZ month of their birth, but some children born late in the month were refracted early in that month and others, for one reason or another, attended during the following month. Thus their ages ranged from 11 to 13 months inclusive.

All the refractions were carried out by the author. When cycloplegia was obviously incomplete, for example, the pupils were mobile or when the refraction changed during retinoscopy, the refraction was excluded. Anybody experienced in refracting children will, however, recognise that there are occasions when complete cycloplegia is in doubt in spite of the pupils being fixed and the refraction appearing to be static, and such children have been included.

The refractions were recorded as before (Ingram, 1977), the basic spherical refraction being that of the less hypermetropic or more myopic meridian for each eye, with any astigmatism (in + cylinders) or anisometropia being recorded separately.

Children found to have squint or congenital abnormalities were managed on traditional lines.

\section{Results}

A variety of clinical and pathological conditions were either identified at the time of screening or previously known (Tables 1 and 2).

A summary of the figures for the basic spherical refraction of individual eyes is given in Table 3 . There is no significant difference between any of these 3 samples of children. Distribution curves drawn for each individual sample are so similar that 1 composite curve is presented (Fig. 1).

Figures for the refractions of children recorded as the basic spherical refraction of the more emmetropic eye are summarised in Table 4. There 
Table 1 Particulars of the sample of children available for screening

\begin{tabular}{llll}
\hline & $\begin{array}{c}\text { Born } \\
1974\end{array}$ & $\begin{array}{c}\text { Born } \\
1975\end{array}$ & $\begin{array}{c}\text { Born } \\
1976\end{array}$ \\
\hline Total number available for screening & 987 & 941 & 896 \\
Number who 'declined' examination & 104 & 139 & 136 \\
$\begin{array}{l}\text { Number who did not attend } \\
\begin{array}{l}\text { Number who attended but were not } \\
\text { fully atropinised' }\end{array}\end{array}$ & 285 & 249 & 216 \\
$\begin{array}{l}\text { Number where refraction was } \\
\text { impossible }\end{array}$ & 2 & 7 & 19 \\
\begin{tabular}{l} 
Number who were refracted \\
\hline
\end{tabular} & 579 & 546 & 523 \\
\hline
\end{tabular}

Table 2

\begin{tabular}{lccc}
\hline & $\begin{array}{c}\text { Born } \\
1974\end{array}$ & $\begin{array}{c}\text { Born } \\
1975\end{array}$ & $\begin{array}{c}\text { Born } \\
1976\end{array}$ \\
\hline Esotropia & 4 & 3 & 3 \\
Esotropia + nystagmus & 1 & - & - \\
Exotropia + dislocated lens & 1 & - & - \\
Coloboma of uveal tract & - & 1 & - \\
Coloboma of uveal tract + esotropia & - & 1 & 1 \\
Congenital cataract & - & 1 & - \\
Congenital nystagmus & - & - & 2 \\
Buphthalmos & - & - & 1 \\
Angioma of eyelid & - & 1 & - \\
Heterochromia iridis & 1 & - & - \\
Gross anomaly of ocular movements & 1 & - & - \\
\hline
\end{tabular}

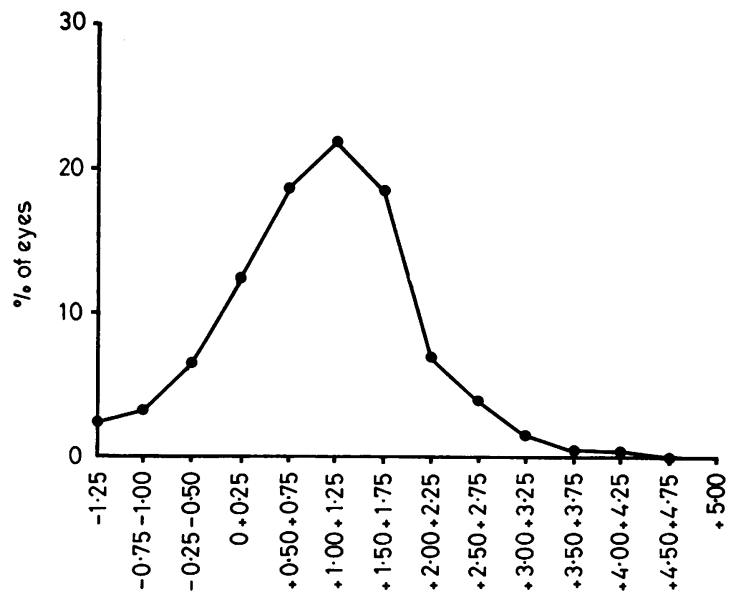

Fig. 1 Spherical refraction of eyes, age 1 year, atropine, $\mathrm{n}=3296$
Table 3

\begin{tabular}{llll}
\hline & Mean & $S D$ & $S E$ \\
\hline Born 1974 & 0.9817 & 1.0181 & 0.0299 \\
Born 1975 & 0.9771 & 1.0626 & 0.0322 \\
Born 1976 & 1.0019 & 0.9865 & 0.0305 \\
\hline
\end{tabular}

Table 4

\begin{tabular}{llll}
\hline & Mean & $S D$ & $S E$ \\
\cline { 1 - 4 } Born 1974 & 0.9593 & 0.9533 & 0.0396 \\
Born 1975 & 0.9270 & 0.9779 & 0.0418 \\
Born 1976 & 0.9136 & 0.9234 & 0.0405 \\
\hline
\end{tabular}

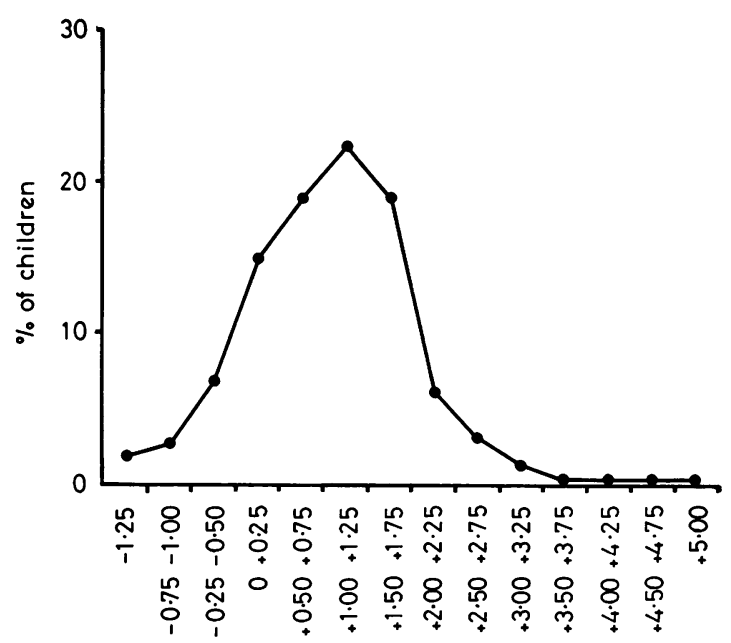

Fig. 2 Spherical refraction of better eye, age 1 year, atropine, $\mathrm{n}=1648$

is no significant difference between any of these 3 samples of children. Again, the distribution curves drawn for each sample are so similar that $1 \mathrm{com}$ posite curve is presented (Fig. 2).

The incidence of astigmatism differs most between children born in 1974 and those born in 1975 . However, this difference is not significant in terms of the numbers of individual eyes with +1.50 or more astigmatism $(P=6.148 \%)$ or of the number of children who had this amount of astigmatism in either or both eyes $(P=59.806 \%)$ (Table 5). The difference in the incidence of children who had anisometropia is most marked when children born in 1974 are compared with those born in 1976, but it is not significant $(P=5.617 \%)$.

The overall incidence of anisometropia was $107 / 1648$, that is, $6 \cdot 5 \%$. The overall incidence of 
Table 5 Incidence of spherical hypermetropia, astigmatism, and anisometropia

\begin{tabular}{|c|c|c|c|}
\hline & Born 1974 & Born 1975 & Born 1976 \\
\hline $\begin{array}{l}\text { Number of children with bilateral spherical hypermetropia of } \\
+2.00 \text { or more DS }\end{array}$ & 77 & 61 & 57 \\
\hline Incidence of bilateral spherical hypermetropia & $13 \cdot 3 \%$ & $11 \cdot 2 \%$ & $10.9 \%$ \\
\hline Number of individual eyes with +1.50 or more $D$ astigmatism & 102 & 123 & 113 \\
\hline Incidence of astigmatism +1.50 or more $D$ in individual eyes & $8 \cdot 8 \%$ & $11 \cdot 3 \%$ & $10 \cdot 8 \%$ \\
\hline $\begin{array}{l}\text { Number of children who had }+1.50 \text { or more } D \text { astigmatism in one } \\
\text { or both eyes }\end{array}$ & 66 & 81 & 71 \\
\hline Incidence of astigmatism +1.50 or more $D$ in one or both eyes & $11 \cdot 4 \%$ & $14.8 \%$ & $13.6 \%$ \\
\hline Number of children who had anisometropia & 45 & 37 & 25 \\
\hline Incidence of anisometropia & $7 \cdot 77 \%$ & $6 \cdot 77 \%$ & $4 \cdot 78 \%$ \\
\hline Incidence of bilateral hypermetropia and/or anisometropia & $104 / 579=17.96 \%$ & $90 / 546=16 \cdot 48 \%$ & $76 / 523=14 \cdot 53 \%$ \\
\hline $\begin{array}{l}\text { Incidence of bilateral hypermetropia and/or astigmatism of } \\
+1.50 \text { or more } D \text { in one or both eyes }\end{array}$ & $131 / 579=22.62 \%$ & $134 / 546=24 \cdot 54 \%$ & $119 / 523=23 \cdot 30 \%$ \\
\hline
\end{tabular}

Table 6 Association between anisometropia and spherical hypermetropia

\begin{tabular}{lcccc}
\hline & \multicolumn{2}{l}{$<+2.00 \mathrm{DS}$} & \multicolumn{2}{l}{+2.00 DS or more } \\
\cline { 2 - 5 } & \multicolumn{1}{l}{ No aniso. } & Aniso. & No aniso. & Aniso. \\
\hline Children born 1974 & 951 & 29 & 162 & 16 \\
Children born 1975 & 912 & 26 & 143 & 11 \\
Children born 1976 & 876 & 13 & 145 & 12 \\
Total & 2739 & 68 & 450 & 39 \\
& & No aniso. & Aniso. & Total \\
$<+2.00$ DS & & 2739 & 68 & 2807 \\
+2.00 or more DS & & 450 & 39 & 489 \\
Total & & 3189 & 107 & 3296 \\
\hline P & & & &
\end{tabular}

$\mathbf{P}=0.0000001 \%$

bilateral spherical hypermetropia was $195 / 1648$, that is $11.83 \%$. The overall incidence of bilateral hypermetropia and/or anisometropia was 270/1648, that is, $16.38 \%$. The overall incidence of bilateral hypermetropia and/or astigmatism was $384 / 1648$, that is, $23.30 \% .13 \cdot 23 \%$ of the children had +1.50 or more $\mathbf{D}$ astigmatism in one or both eyes.

An anisometropic eye is significantly more likely to be hypermetropic, for example, have a basic spherical refraction of $+2.00 \mathrm{DS}$ or more and vice versa (Table 6).

Also a child with bilateral spherical hypermetropia is significantly more likely to have an anisometropic eye and vice versa (Table 7).

An anisometropic eye is significantly more likely to have astigmatism of +1.50 or more $D$ and vice versa (Table 8).
Table 7

\begin{tabular}{|c|c|c|c|c|}
\hline & \multicolumn{2}{|l|}{$<2.00 \mathrm{DS}$} & \multicolumn{2}{|c|}{$\begin{array}{l}+2.00 \text { or more } D S \\
\text { in both eyes }\end{array}$} \\
\hline & No aniso. & Aniso. & No aniso. & Aniso. \\
\hline Children born 1974 & 475 & 27 & 59 & 18 \\
\hline Children born 1975 & 456 & 29 & 53 & 8 \\
\hline Children born 1976 & 447 & 19 & 51 & 6 \\
\hline Total & 1378 & 75 & 163 & 32 \\
\hline$<+2.00 \mathrm{DS}$ & \multicolumn{2}{|c|}{$\begin{array}{l}\text { No aniso. } \\
1378\end{array}$} & $\begin{array}{l}\text { Aniso. } \\
75\end{array}$ & $\begin{array}{l}\text { Total } \\
1453\end{array}$ \\
\hline+2.00 or more $\mathrm{DS}$ & \multicolumn{2}{|c|}{163} & 32 & 195 \\
\hline Total & \multicolumn{2}{|c|}{1541} & 107 & 1648 \\
\hline
\end{tabular}

$\mathbf{P}=0.000001 \%$

Table 8 Association between anisometropia and astigmatism

\begin{tabular}{lllll}
\hline & \multicolumn{2}{l}{$<+1.50 \mathrm{D}$ cyl. } & \multicolumn{2}{c}{$+1.50 \mathrm{D}$ cyl. or more } \\
\cline { 2 - 5 } & No aniso. & Aniso. & No aniso. & Aniso. \\
\hline Children born 1974 & 1039 & 17 & 74 & 28 \\
Children born 1975 & 955 & 14 & 100 & 23 \\
Children born 1976 & 923 & 10 & 98 & 15 \\
Total & 2917 & 41 & 272 & 66 \\
& & No aniso. & Aniso. & Total \\
\hline$<+1.50$ D cyl. & & 2917 & 41 & 2958 \\
+1.50 or more D cyl. & & 272 & 66 & 338 \\
Total & & 3189 & 107 & 3296 \\
\hline P=0.000 000 012\% & & & &
\end{tabular}


Also, a child with $+1.50 \mathrm{D}$ or more astigmatism in either or both eyes is significantly more likely to have an anisometropic eye and vice versa (Table 9).

\section{Discussion}

57 to $59 \%$ of the available children were refracted in each year, but those examined were not necessarily representative of the whole. Information relevant to this point, such as social class, was unfortunately not obtained.

There is no significant difference in the findings of the children born in each of the years 1974, 1975, and 1976 (Tables 1-4). The apparent decrease in the number of anisometropes has possibly arisen

Table 9

\begin{tabular}{|c|c|c|c|c|c|}
\hline & \multicolumn{3}{|c|}{$\begin{array}{l}<+1.50 \mathrm{D} \text { cyl. } \\
\text { in both eyes }\end{array}$} & \multicolumn{2}{|c|}{$\begin{array}{l}+1.50 \mathrm{D} \text { cyl. } \\
\text { in either eye }\end{array}$} \\
\hline & No a & niso. & Aniso. & No aniso. & Aniso. \\
\hline Children born 1974 & 496 & & 17 & 38 & 28 \\
\hline Children born 1975 & 452 & & 13 & 57 & 24 \\
\hline Children born 1976 & 442 & & 10 & 56 & 15 \\
\hline \multirow[t]{2}{*}{ Total } & 1390 & & 40 & 151 & 67 \\
\hline & \multicolumn{3}{|c|}{ No aniso. } & Aniso. & Total \\
\hline \multicolumn{2}{|c|}{$<+1.50 \mathrm{D}$ cyl. in both eyes } & 139 & & 40 & 1430 \\
\hline \multicolumn{2}{|c|}{$\begin{array}{l}+1.50 \text { or more } D \text { cyl. in either } \\
\text { eye }\end{array}$} & \multicolumn{2}{|c|}{151} & 67 & 218 \\
\hline Total & \multicolumn{3}{|c|}{1541} & 107 & 1648 \\
\hline
\end{tabular}

Table 10

\begin{tabular}{llll}
\hline & No aniso. & Aniso. & Total \\
\hline$<+2.00$ DS & 475 & 27 & 502 \\
+2.00 or more DS & 59 & 18 & 77 \\
Total & 534 & 45 & 579 \\
\hline
\end{tabular}

$\mathbf{P}<0.0001 \%$

Table 11

\begin{tabular}{llll}
\hline & No aniso. & Aniso. & Total \\
\hline$<+1.50$ D cyl. & 496 & 17 & 513 \\
+1.50 or more D cyl. & 38 & 28 & 66 \\
Total & 534 & 45 & 579 \\
\hline
\end{tabular}

$\mathbf{P}<0.0001 \%$ because the author became more conscious of the significance of anisometropia, and this might have influenced interpretation of when the retinoscopy shadows actually 'turned'. It is also a timely reminder of how arbitrarily the criteria for 'anisometropia' were selected and that in reality isometropia gradually merges into anisometropia. For example, a child who has 2 eyes with a refraction differing by $+0.75 \mathrm{DS} /+0.75 \mathrm{D}$ cyl. could be more 'anisometropic' than one whose eyes differed by just $+1.00 \mathrm{DS}$ or $+1.00 \mathrm{D}$ cyl.

When the refractions of those children born in 1974 were summarised, it was noted that the incidence of children having hypermetropia and/or anisometropia was $17.9 \%$.6 This was close to the figure of $20 \%$ that had been suggested (Ingram, 1977) might be found in the child population as a whole. Attention then became focused on the incidence of anisometropia alone. Mindful of Ikeda and Wright's (1975) hypothesis that infantile anisometropia might cause stimulus deprivation amblyopia, the finding that $7.77 \%$ of 1 -year-old children born in 1974 had anisometropia seemed particularly interesting, because approximately $7 \%$ of children present at some time with squint and/or amblyopia. There was also a highly significant association in this one year's sample between anisometropia and bilateral spherical hypermetropia (Table 10).

However, there was an even more significant association between anisometropia (of +1.00 or more $D$ sphere and/or +1.00 or more $D$ cyl.) and the presence of +1.50 or more $D$ astigmatism in either or both eyes of a child (Table 11). This association was confirmed in the samples of children born in 1975 and 1976 and also in the overall figures for the 3 years added together: anisometropia and hypermetropia (Table 7, $\mathrm{P}=0.000001 \%$ ); anisometropia and astigmatism (Table 9, $P=0.0000004 \%$ ). This may be a very significant finding and it poses the question whether, if meridional amblyopia is a form of stimulus deprivation amblyopia (Mitchell et al., 1973, Noorden, 1974), 'anisometropic' amblyopia as we understand the term might also be due to stimulus deprivation. It also led us to consider what might be the effects of an abnormal amount of hypermetropia in one or more meridia on the development of vision during the sensitive period (see Ingram et al., 1979).

I thank the following general medical practitioners and their partners for permission to use their premises and staff and to examine their patients: Drs Deutsch, Emanuel, Harlow, Lawson-Matthew, Padget, Shemilt, and Walker. It would have been impossible to do this work without the wholehearted support of their respective health visitors. and I thank them all for the many hours they have spent explaining the reasons for the screening to the mothers and organising the appointments. 


\section{References}

Davidson, S. I. (1976). Mydriatic and cycloplegic drugs. Transactions of the Ophthalmological Societies of the United Kingdom, 96, 327-329.

Ikeda, H., and Wright, M. J. (1975). A possible neurophysiological basis for amblyopia. British Orthoptic Journal, 32, 2-13.

Ingram, R. M. (1977). Refraction as a basis for screening children for squint and amblyopia. British Journal of Ophthalmology, 61, 8-15.

Ingram, R. M., and Barr, A. (1979). Refraction of 1-year-old children after cycloplegia with $1 \%$ cyclopentolate: comparison with findings after atropinisation. British Journal of Ophthalmology, 63, 348-352.

Ingram, R. M., Traynar, M. J., Walker, C., and Wilson, J. (1979). Screening for refractive errors at age 1 year: a pilot study. British Journal of Ophthalmology, 63, 243250.

Mitchell, D. E., Freedman, R. D., Millodot, M., and Haegerstrom, G. (1973). Meridional amblyopia: evidence for modification of the human visual system by early visual experience. Vision Research, 13, 535-558.

Noorden, G. K. von (1974). Factors involved in the production of amblyopia. British Journal of Ophthalmology, 58, 158-164. 